\title{
Community in the city? Social exclusion in neighbourhoods in Hamilton, Ontario, Canada
}

\author{
J. Eyles $^{1}$, K. Wilson ${ }^{2}$, S. Keller-Olaman ${ }^{3}$ \& S. Elliott ${ }^{1}$ \\ ${ }^{I}$ School of Geography and Earth Sciences, McMaster University, Canada \\ ${ }^{2}$ Department of Geography, University of Toronto at Mississauga, \\ Canada \\ ${ }^{3}$ Sunnybrook \& Women's College Health Sciences Centre, \\ Toronto, Canada
}

\begin{abstract}
While an important concern in much of Europe, social exclusion is only now emerging as a significant academic and policy issue in north American cities. This paper examines the nature of social exclusion in two parts of a neighbourhood in Hamilton. The northern part is characterised by lower social status (as measured by employment, education and house ownership) than the southern part. Through a survey and in-depth interviews, individuals in the two sub-neighbourhoods were asked about social interactions, sense of belonging and lifestyle characteristics. Social exclusion was more prevalent in the north and had a negative impact on health.
\end{abstract}

Keywords: community, social exclusion, Hamilton, area programs.

\section{Introduction}

Community remains a powerful but elusive idea despite its presence in academic and policy discourse for many decades. Its continuing power is well-expressed by Amin and Thrift [1, p. 41]. It is worth citing them at length:

"Why has community held such a power to fascinate in the urban literature? There are, we think, five main reasons. To begin with, the history of community has been bedevilled by the idea of a collective, whose members move together and think as one, in a naturalized codependency (Buck-Morss [2]). Then, the community is usually seen as 
able to exist precisely because of the intimacy of face-to-face communication. The community is therefore present to itself, in a world where meaning is unmediated. Then again, the community extends into the past. As tradition, memory plays a crucial role: the present lies heavy under the weight of its legacy. It follows, then, that community is invariably 'local'. Messages pass from hand to hand. Protest takes the form of gatherings. And there is one more reason. Community is able to exist precisely because these kinds of characterizations have allowed it to be visualized, mapped, surveyed, pinned in place. A whole set of knowledges of community has come into existence - in part because of the devotion of an idea of community. Communities' attitudes and values are continually surveyed through various technologies that ensure that communities exist and can be measured (Rose [3])."

Thus as Milligan [4] notes although identities are now largely based on globally available categories and experiences they remain highly local enactments of these categories and experiences. Place-based communities still matter. Important in this matter are then those spatially understood and referenced experiences. Early work on community of course understood this with Sussman [5] emphasizing the importance of social interactions to meet needs and obtain goals. Similar concerns are also found in recent discussions on the continued significance of the neighbourhood, a geographically-bounded 'community', seen as potentially important in an increasingly individualized world with few interactions beyond the household and a small circle of friends. Kearns and Parkinson [6] point to the contextualizing role that neighbourhood plays in shaping personal identity and social position. In greater detail, Forrest [7] examines the different roles that neighbourhood can play. For our purposes, his ideas of neighbourhood as context and as community are most relevant. Thus as context, neighbourhood can affect the quality of local services that can be accessed. It is also important in shaping exposure not only to crime and violence and environmental hazards but also to the processes of socialization in general and whether relationships with broader society might be positive or negative. As community, neighbourhood is shaped by social interactions, networks and neighbourliness. It can help determine patterns of cohesiveness and participation in institutions and social processes. This seems to remain important even in most local social ties are weak rather than strong, helping individuals to feel secure with a sense of belonging rather than forming the basis of most social interactions (see [8]).

Being part of a community or neighbourhood that provides at least weak social ties, an adequate social position and therefore a local basis for person identity seem key characteristics for individuals in the modern city. It is not surprising therefore that neighbourhood has become a vital arena for research and policy with respect to social inclusion/exclusion. 


\section{Social exclusion in the city}

While a relatively recent idea in Canadian discourse, social exclusion has a lengthier history elsewhere. It has been adopted and expanded across Europe as there is dissatisfaction with the narrow focus of such concepts as poverty, deprivation and material welfare $[10,11]$. While social exclusion is related to poverty and unemployment, Atkinson [12], p.v cautions against equating these terms: "People may be poor without being socially excluded; and others may be socially excluded without being poor". In fact, social exclusion focuses on the processes that prevent individuals from participating in economic, social, and political dimensions of society.

Social exclusion has thus been defined as "a short hand term for what can happen when people or areas suffer from a combination of linked problems such as unemployment, poor skills, low incomes, poor housing, high crime, bad health and family breakdown" $[13$, p. 11] with an individual being socially excluded if he or she does not participate in key activities of the society in which he or she lives. Social exclusion is also thought to have indirect costs for society at large, such as, a lack of social cohesion, higher crime and fear of crime, increased pressure on the social services system and increased stigma associated with particular neighbourhoods or geographic areas. And from an economic perspective, exclusion is argued to be a key component of increased public spending to combat crime and substance abuse, reduce homelessness, and provide social and health services [13].

This paper contributes to this growing area of research by examining social exclusion within the context of neighbourhoods. While international research has documented the links between neighbourhood environments and social exclusion e.g., [14] very little research conducted in Canada has addressed the relationship between neighbourhoods and social exclusion. As such, we examine the extent to which processes of social exclusion differ between two adjacent but socially contrasting neighbourhoods in Hamilton, Ontario, Canada.

\section{Data and methods}

This research is part of a larger project designed to examine social determinants of health at the neighbourhood level. The project collected data through a crosssectional neighbourhood telephone survey conducted in four neighbourhoods in Hamilton. A detailed description of the neighbourhood selection process is found in Luginaah et al. [15].

One neighbourhood, Chedoke-Kirkendall, represented a diverse one and in fact contained two distinct sub-areas - a north and south neighbourhood differentiated by social and population characteristics. Data from the 1996 Census of Canada reveals that the population in North Chedoke-Kirkendall is characterized by lower levels of education, income and higher levels of unemployment as well a higher percentage of the population rents their dwelling (see Table 1). While both neighbourhoods contain a similar percentage of immigrant populations, there are more members of the population from visible 
minority groups in the north neighbourhood. Thus in close proximity there appears to be two areas that might exhibit different types of social exclusion/inclusion. To explore this, our research was carried out in two stages.

Table 1: $\quad$ North and South Chedoke-Kirkendall, 1996 census characteristics.

\begin{tabular}{|l|c|c|}
\hline Characteristics & South (\%) & North (\%) \\
\hline High school or more & 85 & 53 \\
\hline Below Low Income Point (\$30,000) & 33 & 56 \\
\hline Unemployed & 11 & 12 \\
\hline Housing Tenure (Rent) & 22 & 33 \\
\hline Visible Minorities & 5 & 8 \\
\hline Recent Immigrants & 2.5 & 2 \\
\hline Foreign Born & 21 & 19 \\
\hline Single & 67 & 60 \\
\hline
\end{tabular}

Source: 1996 Census of Canada.

Table 2: Aspects of social exclusion in North and South ChedokeKirkendall.

\begin{tabular}{|c|c|c|}
\hline Dimension of Exclusion & $\begin{array}{c}\text { South } \\
(\%)\end{array}$ & $\begin{array}{c}\text { North } \\
(\%)\end{array}$ \\
\hline \multicolumn{3}{|l|}{ Consumption/Production } \\
\hline Below Low Income Point $(\$ 30,000)$ & 14 & 28 \\
\hline Unemployed & 22 & 36 \\
\hline Does not own home & 14 & 23 \\
\hline Worry monthly about bills & 9 & 22 \\
\hline Not enough food due to lack of money & 1 & 5 \\
\hline Does not have a regular family doctor & 5 & 4 \\
\hline Seen/talked with doctor in past 2 weeks & 12 & 18 \\
\hline Unmet health care needs & 6 & 12 \\
\hline No Insurance for prescription medication & 24 & 30 \\
\hline No Insurance for dental expenses & 24 & 29 \\
\hline No Insurance for primate/semi-private hospital room & 27 & 34 \\
\hline \multicolumn{3}{|l|}{ Neighbourhood Engagement/ Social Interaction } \\
\hline$<$ median number of close friends $(6)$ & 39 & 42 \\
\hline$<$ median number of close relatives $(5)$ & 43 & 41 \\
\hline Little or no involvement in organizations & 68 & 73 \\
\hline Dissatisfied with neighbourhood & 1 & 6 \\
\hline Considered moving in past 12 months & 30 & 28 \\
\hline Want to move outside neighbourhood & 41 & 51 \\
\hline Does not like anything about their neighbourhood & 4 & 7 \\
\hline Dislikes at least one thing about their neighbourhood & 64 & 64 \\
\hline
\end{tabular}

Source: Hamilton, Ontario Neighbourhood Health Survey, 2001-2002. 
In the first stage, we analysed the neighbourhood survey data by exploring differences in neighbourhood perceptions, social and community networks, as well as other measures of exclusion/inclusion between the two areas. In the second stage of the research, 40 in-depth interviews were conducted with 10 men and 10 women in the north and south sub-areas. The purpose of the interviews was to examine residents' participation in formal and informal neighbourhood events/activities, connections with neighbours, as well as perceptions of their neighbourhood.

We analyze both the survey and interview data by drawing upon the framework of social exclusion proposed by Burchardt et al. [16]. They outline four main activities from which individuals may be excluded: Consumption the ability to purchase goods and services; Production linked to involvement in social and economic activities; Political Engagement involvement in local or national level decision-making; and Social Interaction involvement with family, friends and the broader community. Since our focus is exclusion at the neighbourhood level, we replace the category of Political Engagement with Neighbourhood Engagement, referring to an individual's participation in formal neighbourhood activities and decision-making processes, as well as their overall satisfaction with their neighbourhood environment. From the survey we include a number of variables to represent each of the four dimensions.

\section{Findings}

\subsection{Consumption and production}

Differences in production and consumption activities are quite evident between the two neighbourhoods (see Table 2). Approximately twice as many residents in the north have a household income that is below \$30,000 (Statistics Canada Low-Income Cut-Off (LICO)), a higher percentage are unemployed, and a lower percentage own their own home as compared to residents in the south. A higher percentage of residents in the north report that they worry every month about being able to pay their bills and that they have experienced times when they did not have enough food to eat due to a lack of money. In terms of health care use and access few respondents in both neighbourhoods report that they do not have a regular family doctor. However, almost $20 \%$ of individuals in the north have seen or talked to their doctor in the past two weeks as compared to only $12 \%$ of those in south. Interestingly, twice as many respondents in the north than in the south neighbourhood report that they did not receive health care when they needed it.

In general, interview respondents from the north neighbourhood have lower rates of home ownership and education and higher rates of unemployment. The north neighbourhood also contains a lower quality housing stock. Some individuals mentioned that while they do not like living in their neighbourhood they are forced to because of the inexpensive price of housing. Julia, who is unemployed and has been living in the north neighbourhood for 17 years, 
commented that she wants to move from this neighbourhood but cannot afford to leave:

"I want a place that is mine. What I can afford in the city, is not worth buying because they are in areas I will not live in or a dinky little house that isn't much bigger than my apartment."

In contrast, no one in the south stated that they disliked living there. In fact, many decided to move there because of its attractive qualities. For example, Arthur has been living in the south neighbourhood for 16 years. He moved to the area because of its good reputation:

"It is a pleasant setting to live. It is a scenic road. It is called the most attractive street in Hamilton. It is not quite rural but it is not quite central city and yet we are very close to the highway, close to downtown, close to anything you want to do.

Sharon described South Kirkendall as one of the best neighbourhoods in the city:

"Well, southwest has a lot of character. The people are nice. They are usually in a white collar, fairly educated and it's a very friendly neighbourhood really. You walk down the street, they say 'hi' to you and I'm fond of very old homes. I love this neighbourhood. I'd have to say this is one of the nicest, the best in Hamilton."

\subsection{Neighbourhood engagement and social interaction}

Neighbourhood engagement and social interaction are interrelated constructs, although the former tends to be more formal (e.g., sports teams, church membership) and the latter more informal (e.g., day-to-day talks with neighbours). The survey data show few differences between the north and south neighbourhoods with respect to number of close friends and relatives (see Table 2). The data also reveal that, in general, a higher percentage of respondents in the north are unhappy with their neighbourhood. For example, approximately $6 \%$ of north residents are dissatisfied with their neighbourhood as a place to live as compared to only $1 \%$ of respondents in the south. Similarly, a higher percentage of individuals living in the north report that they do not like anything about their neighbourhood.

Even though the street-by-street neighbourhood inventory revealed more opportunities in the north to participate in neighbourhood-level activities (i.e., the existence of parks and recreation centres), in general, more individuals from the south reported that they are involved in various clubs and activities both within and outside their neighbourhood. Individuals from the south are members of a variety of formal organizations including religious, political, cultural, athletic and environmental groups. For example, Stacey, who has lived there for 9 years, describes her involvement in numerous neighbourhood activities: 


\begin{abstract}
"Well this is quite an area. It is called Kirkendall and there is a Kirkendall Association. You get together. They have various activities through the year. There is some fund raisers we have in the park that raise money for...we bought playground equipment at the Triple-A grounds. You know, there are some activities and we have local soccer in the park. They have put together their own soccer league and I have coached that."
\end{abstract}

While not all individuals in the south are involved in formal activities and organizations, few individuals in the north reported any participation in formal neighbourhoods clubs or organizations. Even more interesting is the finding that reasons for lack of participation are very different between the two areas. When asked about the factors that prevent them from participating in neighbourhood activities, respondents in the south cited a lack of time due to work commitments or a lack of interest.

"If I was around more, I would participate more. I would join the running club." (Peter)

In contrast, residents from the north most often mentioned financial constraints or health problems as factors that prevent them from joining clubs. For example, Paul is a former Cub Scout leader and he discussed how registration fees are a financial barrier to participation for many households in the north:

"There's a few Scout troops around our house. A lot but the price of the Scouting is getting so high... Scouting for two kids, three kids you're looking at three hundred bucks, just to say 'You can go', not to mention buying their uniform."

Individuals in both areas interact informally with their neighbours although the degree and type of interactions are quite different between the north and south. Residents in the south interact frequently with their neighbours. Although there are fewer restaurants and coffee shops in the south than in the north neighbourhood, many residents from the south meet for daily walks or at local coffee shops each morning or evening. In addition, some women in the south have organized a book club:

"The nature, the greenery, the space, the sense of space, are all very, very positive...There is a regular brigade of people that walk their dogs down on the golf course. A lot of them especially in the winter when it is dark they go down to protect each other. I think they appreciate the closeness of this as well". (Katie) 
Many residents in the north also indicated that they have friendly interactions with their neighbours. Individuals can rely on one another to keep an eye on their houses while they are away and some will engage spontaneously in conversation but very few indicated that they interact on a regular basis with the neighbours. In contrast to circumstances in the north, it appears that the regular, often daily, interaction with neighbours has allowed residents in the south to create a sense of community:

\begin{abstract}
"We certainly felt that we were part of the community...You become part of the school, and then part of that community, part of the church community, and then you start to know other people. That's where we really started to meet people in the neighbourhood...The women - Moms - that I met the very first year are the ones that I still know and am friends with." (Barbara)

"It (interacting with friends at Tim Horton's) gives us a sense of community. It's not just stuck in the middle of a big city. There's this little community that keeps the pulse on what's going on...We're very comfortable here. We feel very secure." (Richard)
\end{abstract}

This sense of community appears to allow residents in the south to work together to make changes in their neighbourhood. For example, Barbara talked about her involvement in raising money to redevelop the neighbourhood park:

"The city was putting forth money to redevelop the park and something came in the paper saying that they were putting on a presentation about what that might be. The neighbourhood association ... so I thought, well, I'll go because I live across from the park to see what's what. ...I ended up becoming the Chair of the fund raiser committee, because I have a hard time saying no."

Very few residents in the north mentioned that they felt a strong sense of community in their neighbourhood. Perhaps this lack of a community feeling leads some to feel like they cannot make positive changes to their neighbourhood. For example, Jim has lived in the area for 9 years but feels that he cannot make a difference when it comes to solving problems in his neighbourhood:

"There are people who come at night and they will rifle through your car to find anything inside it, like open the cigarette ashtray looking for change, under the seats, if it's not locked...it bothers me a lot, but there doesn't seem to be too much we can do about it except lock stuff up...we reported it to the police every time, which gets us nothing." 


\section{Discussion and conclusion}

Our research confirms that exclusion involves the interconnection of a lack of economic productivity, consumption of necessary goods and services, neighbourhood engagement and social interaction. If anything, our results suggest that exclusion may or may not involve the combination of any of the four dimensions. For example, there are individuals in the north who do not feel socially excluded and conversely those in the south who do not feel socially included. Further, there are individuals in the north who are economically productive yet do not feel a part of their neighbourhood. In contrast, there are those who are not economically productive, do not have the means to acquire many of life's basic necessities but feel like they are an important part of their neighbourhood. Perhaps then, as Burchardt et al. [16] suggest, exclusion/ inclusion is part of a continuum, with individuals potentially falling below some threshold level on some items and above on others. Regardless of what combination of factors produces exclusion/inclusion, various aspects of it exist in both neighbourhoods and may have important affects on health. Furthermore our research shows that positive interactions with neighbours and engagement with the local community enhance health in a number of ways, including the encouragement of healthy lifestyles and the building of strong communities. Recent research in deprived neighbourhoods in the UK suggests that neighbourhood environments shape local social capital and this in turn shapes health (see [17]).

European governments have not only addressed social exclusion but also recognize its devastating effects on their citizens and have implemented policies to minimize the effects. In Canada, the intellectual engagement as a political precursor of policy development appears to be beginning. As Evans and Advokaat [18] note for the Law Commission of Canada, inclusion and the struggle against exclusion are necessary elements for strong public life and vitality. Much effort has been expended in Europe on area programs to combat exclusion [19] but there is always political pressure to extend these initiatives and they need to be integrated with other regional strategies concerning infrastructure, employment and so on. It is uncertain how well area programs are working. They may improve access to resources and decision-making. But combating exclusion and reinventing community are long-term goals.

\section{References}

[1] Amin, A. and Thrift, N. Cities: reimagining the urban, Polity Press: Oxford, 2002.

[2] Buck-Morss, S. Dreamworld and Catastrophe, MIT Press: Cambridge, MA, 2000.

[3] Rose, N. Powers of Freedom, Cambridge University Press: Cambridge, 1999.

[4] Milligan, M. Displacement and identity discontinuity, Symbolic Interaction 26, pp. 381-403, 2003. 
[5] Sussman, M.B. Community Structure and Analysis, Crowell: New York, 1959.

[6] Kearns, A. and Parkinson, M. The significance of neighbourhood, Urban Studies 38, pp. 2103-2110, 2001.

[7] Forrest, R. Who Cares about Neighbourhood? Community Neighbourhood Research Paper 26, 2004.

[8] Henning, C. and Lieberg, M. Strong or weak ties? Scandinavian Housing and Planning Research 13, pp. 3-26, 1996.

[9] Burchardt, T., LeGrand, J. and Piachaud, D. Introduction, Understanding Social Exclusion, eds. J. Hills, J. LeGrand and D. Piachaud, Oxford University Press: Toronto, pp. 1-12, 2002.

[10] Guildford, J. Making the Case for Economic and Social Inclusion, Atlantic Regional Health Office, Health Canada, 2000.

[11] Littlewood, P. and Herkammer, S. Identifying social exclusion, Social Exclusion in Europe, ed. P. Littlewood, Ashgate Publishing: Aldershot, 1999.

[12] Atkinson, A.B. Preface, Exclusion, Employment and Opportunities, eds. A.B. Atkinson and J. Hills, Centre for the Analysis of Social Exclusion: London, 1998.

[13] Social Exclusion Unit, Preventing Social Exclusion, Cabinet Office: London 2001.

[14] Buck, N. Identifying neighbourhood effects on social exclusion, Urban Studies 38, pp. 2251-2275, 2001.

[15] Luginaah, I. et al. Health profiles of Hamilton, Geoforum 53, pp. 135-147, 2001.

[16] Burchardt, T., LeGrand, J. \& Piachaud, D. Degrees of social exclusion, Understanding Social Exclusion, eds. J. Hills, J. LeGrand, D. Piachaud. Oxford University Press: Toronto, pp. 30-43, 2002.

[17] Cattell, V. Poor people, poor places and poor health, Social Science \& Medicine 52, pp. 1501-1516, 2001.

[18] Evans, H. \& Advokaat, E. The language of communicating in Canada, Law Commission: Ottawa, 2001.

[19] Parkinson, M. Combating Social Exclusion: Lessons from Area-Based Programs in Europe, Policy Press: York, 1998. 